\title{
CHARACTERIZING A SOURCE OF FISSION FRAGMENTS FOR A GAS JET
}

\author{
R. N. CEO,*+ H. C. GRIFFIN, ${ }^{*}$ K. RENGAN** \\ *Department of Chemistry, University of Michigan, MI 48109 (USA) \\ **Chemistry Department, Eastern Michigan University, Ypsilanti, MI 48197 (USA)
}

(Received March 13, 1990)

\begin{abstract}
A model for the rate at which various primary fission products stop in the gas of the source chamber of a gas jet has been constructed. It describes the absorption of fission fragments in Al foils placed between the ${ }^{235} \mathrm{U}$ deposit and the gas chamber as well as the penetration of fragments through the gas. The model is based on reported ranges (mean values as a function of $\mathrm{A}$ and the dispersion in ranges) and measured activities of $\mathrm{Kr}$ and $\mathrm{Xe}$.
\end{abstract}

\section{Introduction}

The gas jet facility ${ }^{1}$ at the Ford Nuclear Reactor was set up to study the chemical forms of fission products which have stopped in various gases. Since the chemical forms of primary fission products (before beta-decay) may differ from the forms of secondary products (after beta-decay of one or more precursors), the gas jet is needed to rapidly transport the products from near the reactor core to the site for chemical processing and counting. The $\boldsymbol{\gamma}$-ray spectra of gross fission products are quite complex and the products include pairs of elements (one from the light group and one from the heavy group) with similar chemical characteristics. ZENDEL et al. ${ }^{2}$ have shown that a suitable foil between the fission source and the gas can nearly eliminate the heavy group of fission products.

To assess transport, separation, or collection efficiency for any fission product delivered by the gas jet, it is necessary to know the rate at which the species is deposited into the carrier gas from the target. Because of the barrier foils, this rate is quite different from fission yields. ${ }^{3}$ In general, the rate cannot be measured directly, but it may vary as the foil ages or the position of the ${ }^{235} \mathrm{U}$ relative to the reactor core changes.

The inert gases $\mathrm{Kr}$ and $\mathrm{Xe}$ can be expected to avoid reactions with the carrier gas and with the inner surfaces of the gas passageway. Quantitative recovery, except for a

\footnotetext{
${ }^{+}$Present address: Analytical Chemistry Division, Oak Ridge National Laboratory, Oak Ridge, TN, USA.
} 
decay in transit, should be possible. Our method of characterizing the rate at which various primary fission products stop in the gas is based on these expectations.

\section{Experimental}

\section{Methods}

Two methods have been developed for indirect determination of the target's fission rate using $\gamma$-ray spectra of the noble gases and their decay products. The delivery rates of short-lived ( $<40 \mathrm{~s}$ ) $\mathrm{Kr}$ and $\mathrm{Xe}$ were measured directly with an online technique ("coil"), and delivery rates of longer-lived species were inferred from the activities of their decay products using a batch technique ("balloon").

The gas jet target chamber contained $1 \mathrm{mg}$ of ${ }^{235} \mathrm{U}$ chemically plated on an aluminum plachet and covered by a set of thin foils with a total thickness of 2.57 $\mathrm{mg} \cdot \mathrm{cm}^{-2}$. The barrier foils absorb most of the heavy fission products without removing as large a fraction of the light products. The survivors penetrate the foil, stop in the gas, and are swept away from the target.

$\mathrm{Kr}$ and $\mathrm{Xe}$ are readily transported by any carrier gas; prepurified nitrogen was used since it does not transport other fission products efficiently. ${ }^{4}$ Gas entered the target chamber at about atmospheric pressure, passed through the transport and detection system, and exhausted through a large charcoal filter where the pressure was less than 0.1 bar. The nominal flow rate of nitrogen was $40 \mathrm{ml} \cdot \mathrm{s}^{-1}$ at standard temperature and pressure.

\section{On-line technique using coil}

Delivery rates of ${ }^{90-94} \mathrm{Kr}$ and ${ }^{139-142} \mathrm{Xe}$ to the detector coil were determined using a modification of the two-detector delay method described by ALSTAD et al. ${ }^{5}$ Two consecutive spectra were acquired as the fission product laden carrier gas passed through a coil of polyethylene tubing surrounding a Ge detector. The first spectrum was from an undelayed gas sample; the path between target and detector was kept as short as possible. The second spectrum was from a gas sample which had been delayed by passage through a tube interposed between the target and the detector coil.

The detector coil, fabricated from $2.26 \mathrm{~m}$ of $4.0 \mathrm{~mm}$ ID polyethylene tubing, was $7.5 \mathrm{~cm}$ diameter by $5.6 \mathrm{~cm}$ long and encircled the detector cryostat so that the Ge element was surrounded by the gas sample. For moderately energetic $\gamma$-rays the detection efficiency was nearly independent of position in the coil. An absolute 
efficiency curve was constructed for the coil/detector geometry by filling the coil with a ${ }^{140} \mathrm{La}$ solution which had been standardized against an NBS-traceable mixed nuclides standard.

The 16-m length of the delay line was based on preliminary tests and was chosen so that about half of 1.84 second ${ }^{92} \mathrm{Kr}$ and 1.29 second ${ }^{93} \mathrm{Kr}$ would decay while passing through it. The measured residence time of the detector coil was 0.26 (estimated standard deviation $=0.04$ ) seconds. This implies that the gas in the coil was at a pressure of about 0.3 bar.

Typical count rates were $4000 \mathrm{~s}^{-1}$. The spectra contained about 300 significant peaks, which included many decay products as well as the short-lived noble gases.

\section{Batch technique using balloon}

Although ${ }^{88} \mathrm{Kr},{ }^{89} \mathrm{Kr}$, and ${ }^{138} \mathrm{Xe}$ are produced in good yield from thermalneutron-induced fission of ${ }^{235} \mathrm{U}$, their half-lives are too long to permit direct observation of their decays during the 0.26 second residence in the detector coil of the on-line method described above. Instead, a technique was developed which permitted indirect measurement of the release rates of these nuclides by counting their decay products and applying growth and decay corrections to the observed activities. In this technique, a balloon was filled with a gas sample, the gas was retained in the balloon to allow noble gases to disintegrate and decay products to build up. Then the gas was exhauseted from the balloon, the balloon was rolled up and placed in front of a $\mathrm{Ge}$ detector, and the decay products were counted. The decay products were expected to be non-volatile and to adhere to inner wall of the balloon, remaining inside when the balloon was deflated; this was verified by exhausting the balloon through a quartz. wool filter and examining the filter for the decay products $\mathrm{Rb}, \mathrm{Sr}$ and $\mathrm{Cs}$.

As in the on-line method, prepurified nitrogen was used as the carrier gas to minimize the transport of non-gaseous fission products.

An absolute efficiency curve was constructed for the balloon/detector geometry by filling a $20 \mathrm{~cm}^{3}$ scintillation vial with a ${ }^{140}$ La solution which had been standardized against an NBS-traceable mixed nuclides standard; the scintillation vial, which had the same shape and dimensions as the rolled-up balloon, was counted in the same position as the balloon.

The balloon was inflated for 900 seconds to a volume of 391 and a pressure just above atmospheric. After a holding time of 3600 seconds, the balloon was deflated in 90 seconds and counted for 1800 seconds. Typical spectra contained 70-100 peaks with a significance greater than 2 standard deviations above the continuum. All of the intensity was accounted for by $\mathrm{Rb}, \mathrm{Sr}, \mathrm{Cs}, \mathrm{Ba}$, and small amounts of $\mathbf{I}$. 


\section{R. N. CEO et al.: CHARACTERIZING A SOURCE OF FISSION FRAGMENTS}

Analysis of $\gamma$-ray spectra

All of the spectra were sufficiently uncertain, either from poor statistics or overlapping peaks, that interpretation in terms of activities of particular nuclides required careful examination of all expected peaks and their relative intensities. First, each peak was weighted inversely with the square of its statistical error. Then rate determining peaks - those which set tight upper limits on activities - were identified. For peaks with excess intensity, some attempt was made to identify other contributions. Even if all of the contributions could not be identified, these peaks were given small weighting factors to remove them from the computation of nuclidic activities. In general there was agreement among several $\boldsymbol{\gamma}$-rays for each activity determination.

\section{Calculation of attenuation in barrier foils}

\section{Fission product range}

VANDENBOSCH and HUIZENGA ${ }^{6}$ have reported that typical lightmass fission fragments have mean ranges from 2.28 to $1.84 \mathrm{mg} \cdot \mathrm{cm}^{-2}$ in Al. The range depends on $A$ and $Z$, and also depends on the subtle effects shell closure has on total fission energy. Ranges for several specific fission products in Al have been published by SUZOR, ${ }^{7}$ ALEXANDER and GALLAGHER, ${ }^{8}$ and FINKLE et al. ${ }^{9}$ These values are plotted in Fig. 1. The curve shows the range values used in our model.

$\mathrm{KATCOFF}$ et al. ${ }^{10}$ reported that differential range curves for fission products are approximately Gaussian, with FWHM $=11.7 \%$ of the mean range. The dispersion in the range is more due to differences in initial particle energies than it is to actual straggling of the particles. The transmission factors obtained in the present work were computed using mean ranges shown by the curve in Fig. 1 and a dispersion of $11.7 \%$ (FWHM).

For the recoiling nucleus to stop in the gas, it must be projected toward the gas, penetrate the foil, but not penetrate the gas and embed itself in the far wall of the target chamber.

\section{Angle-dependent foil penetration}

The length of the fission fragment's track, $t_{A_{1}}(\theta)$, through the $\mathrm{Al}$ foil of thickness $\mathrm{t}_{\mathrm{A} \text { I }}$ increases with increasing angle $\theta$ from the normal

$$
t_{A 1}(\theta)=t_{A 1} \cdot \sec \theta
$$




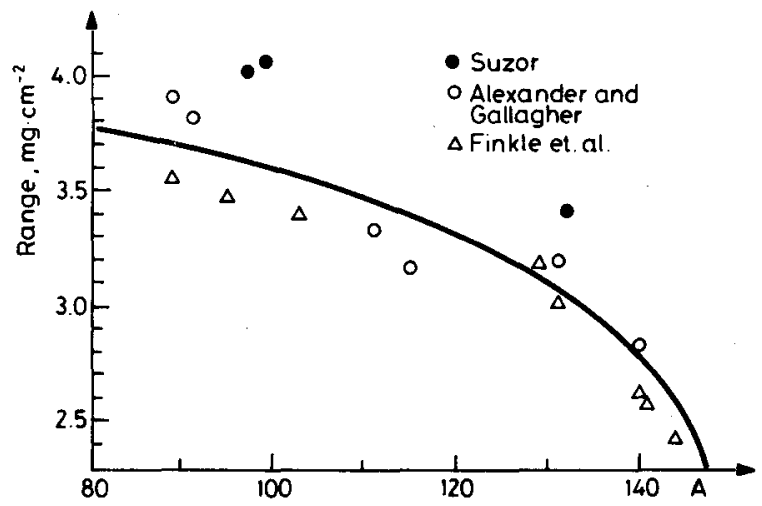

Fig. 1. Mean ranges of ${ }^{235} \mathrm{U}$ fission fragments in Al. The data are from References 7-9. Values used in the model are given by the line

The fraction of particles along each track which stop in the gas can be calculated using the integral of the Gaussian distribution $G(t)$ centered at the mean range and with $11.7 \%$ FWHM. Three cases are represented by the shaded areas shown in Fig. 2.

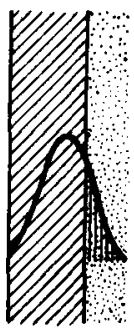

1

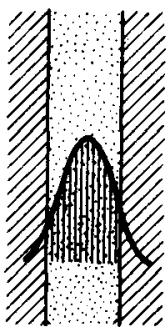

2



3

Fig. 2. Typical cases for calculation of transmission fractions

They correspond to

Case 1: $\mathrm{R}<\mathrm{t}_{\mathrm{A} I}(\theta)$,

Case 2: $\mathrm{t}_{\mathrm{Al}}(\theta)<\mathrm{R}<\mathrm{t}_{\mathrm{Al}+\mathrm{gas}}(\theta)$,

Case 3: $\mathrm{R}>\mathrm{t}_{\mathrm{Al}+\mathrm{gas}}(\theta)$

where $R$ is the estimated mean range for a given noble gas nuclide and $t_{A 1+g a s}(\theta)$ is the combined mass thickness of the foil plus the gas in the target chamber. 


\section{Overall transmission yields}

Transmission yields were computed by summing the weighted angle-dependent transmission fractions in steps of 1 degree from 1 to 89 degrees from a normal to the foil surface; the results are shown in Table 1. Note that for the light-mass fission

Table 1

Transmission yields. The yield is defined as the fraction of primary fission products which stop in the gas

\begin{tabular}{cc}
\hline Mass & Yield \\
\hline 88 & 0.181 \\
89 & 0.179 \\
90 & 0.177 \\
91 & 0.176 \\
92 & 0.173 \\
93 & 0.171 \\
94 & 0.169 \\
138 & 0.057 \\
139 & 0.048 \\
140 & 0.033 \\
141 & 0.025 \\
142 & 0.019 \\
\hline
\end{tabular}

products, the transmission yield drops off rather slowly with increasing mass, while for the heavier-mass analogs, the yield drops off much faster. Clearly a slightly thicker foil $\left(>2.75 \mathrm{mg} \cdot \mathrm{cm}^{-2}\right.$ ) would effectively stop the heavy-mass fission fragments and still pass most of the lighter particles, allowing much cleaner $\gamma$-ray spectra of the ${ }^{-}$ light-mass species. However, without at least some of the xenons with substantially different ranges, we could not have tested the model sufficiently to have confidence in predictions for products distinctly different from $\mathrm{Kr}$.

\section{Results}

Delivery rates of noble gases

RENGAN and GRIFFIN ${ }^{1}$ have previously determined the transit time from the target to the detector. With corrections for changes in the length and size of tubing, the transit time is $0.8 \pm 0.2$ seconds. This value was used, along with delivery rates, 
to compute deposition rates for the observed noble gases. These are listed in Table 2. The errors given in parentheses are estimated standard deviations based on counting statistics only. (In some cases these errors are unrealistic ${ }_{+}$.The minimum real uncertainty is $5 \%$ ).

Table 2

Noble gas deposition rates and inferred fission rates. The values in parentheses are estimated standard deviations from counting statistics

\begin{tabular}{crrr}
\hline \multirow{2}{*}{ Nuclide } & \multicolumn{2}{c}{ Deposition rates $\times 10^{3} \mathrm{~s}^{-1}$} & $\begin{array}{c}\text { Fission rate, } \\
\times 10^{5} \mathrm{~s}^{-1}\end{array}$ \\
\cline { 2 - 4 } & \multicolumn{1}{c}{ Coil } & Balloon & \\
\hline${ }^{88} \mathrm{Kr}$ & & $112(3)$ & $186(5)$ \\
${ }^{89} \mathrm{Kr}$ & & $116(2)$ & $149(3)$ \\
${ }^{90} \mathrm{Kr}$ & $144(11)$ & & $156(12)$ \\
${ }^{91} \mathrm{Kr}$ & $76(6)$ & $105(4)$ & $146(7)$ \\
${ }^{92} \mathrm{Kr}$ & $37(3)$ & $34(2)$ & $106(6)$ \\
${ }^{93} \mathrm{Kr}$ & $12(1)$ & & $91(7)$ \\
${ }^{138} \mathrm{Xe}$ & & $70(9)$ & $185(6)$ \\
${ }^{139} \mathrm{Xe}$ & $41(4)$ & $45(2)$ & $146(6)$ \\
${ }^{140} \mathrm{Xe}$ & $21(2)$ & & $159(15)$ \\
${ }^{14} \mathrm{Xe}$ & $6(1)$ & & $179(25)$ \\
\hline
\end{tabular}

\section{Calculation of fission rate}

Since the delivered fission products all originated from the same fissioning target, their deposition rates should, in principle, all yield the same result when used to calculate the source's fission rate. Parameters for these calculations include noble gas deposition rates, cumulative fission yields, and barrier transmissions. These fission rates are given in Table 2 . As with the delivery rates, the errors are estimated standard deviations. Minimum real uncertainties are $10 \%$.

\section{Discussion}

The calculated fission rates show a clear trend toward lower values for the heavier krypton isotopes. This may result from too crude an estimate of ranges. Fragments in the wings of the yield distribution may have lover kinetic energies and shorter ranges than predicted in our simple model. This effect would not show in these data for light $\mathrm{Kr}$ isotopes, because they are produced by beta decay of short-lived precursors which have typical kinetic energies. The heavy isotopes are atypical. 
The apparent trend might arise from an underestimate in the transit time from the fission target to the counting position. One piece of evidence that our transit times are not far off is the detection of 0.21 second ${ }^{94} \mathrm{Kr}$ and 1.2 second ${ }^{142} \mathrm{Xe}$ in the "coil" measurements. Our data imply that the most abundant $\gamma$-ray $(629.3 \mathrm{keV})$ of ${ }^{94} \mathrm{Kr}$ occurs in more than $80 \%$ of its decays. If the transit time were longer than assumed, the inferred fraction would have been higher. Unless this " $\gamma$-ray" consists of more than one component, it cannot be greater than $100 \%$.

One of the authors (KR) thanks Eastern Michigan University for providing support through the Faculty Research Fellowship Program. The support received through the U. S. Department of Energy Cost Sharing Program (Grant \#DEFG028 ER10724) is also gratefully acknowledged.

\section{References}

1. K. RENGAN, H. C. GRIFFIN, J. Radioanal. Nucl. Chem., 98 (1986) 255.

2. M. ZENDEL, K. RENGAN, T. N. MASSEY, S. G. PRUSSIN, R. A. MEYER, Nucl. Inst. Methods, A256 (1987) 180.

3. E. A. C. CROUCH, Atomic Data and Nuclear Data Tables, 19 (1977) 486.

4. H. DAUTET S. GUJRATHI, W. J. WIESEHAHN, J. M. D'AURIA, B. D. PATE, Nucl. Instr. Methods, 107 (1973) 49.

5. J. ALSTAD, T. BJORNSTAD, G. SKARNEMARK, Nucl. Instr. Methods, A244 (1973) 490.

6. R. VANDENBOSCH, J. R. HUIZENGA, Nuclear Fission, Academic Press, New York, 1973, p. 312.

7 F. SUZOR, Ann. Phys., 4 (1949) 269.

8. J. ALEXANDER, M. F. GALLAGHER, University of Califomia, Lawrence Radiation Laboratory Report, UCRL-8078, 1959.

9. B. FINKLE, E. J. HOAGLAND, S. KATCOFF, N. SUGARMAN, Papers 45 and 46 , in: Radiochemical Studies: The Fission Products, C. D. CORYELL and N. SUGARMAN (Eds), McGrawHill, New York, 1951.

10. S. KATCOFF, J. A. MISKEL, C. W. STANLEY, Phys. Rev., 74 (1948) 631. 